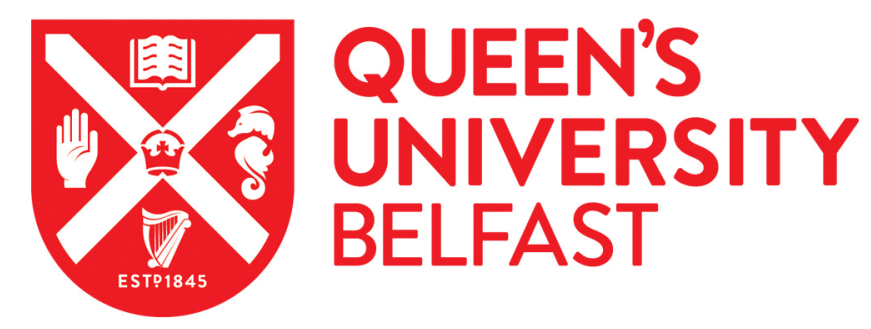

\title{
Bearing Witness to Child Abuse and Trauma in Pilar Acevedo's Multimedia 'Fragmentos' Exhibition
}

\author{
Bowskill, S. E. L. (2018). Bearing Witness to Child Abuse and Trauma in Pilar Acevedo's Multimedia \\ 'Fragmentos' Exhibition. Bulletin of Spanish Visual Studies, 2(1), 105. \\ https://doi.org/10.1080/24741604.2018.1453017
}

\section{Published in:}

Bulletin of Spanish Visual Studies

\section{Document Version:}

Peer reviewed version

\section{Queen's University Belfast - Research Portal:}

Link to publication record in Queen's University Belfast Research Portal

\section{Publisher rights}

(C) 2017 Bulletin of Spanish Visual Studies. This work is made available online in accordance with the publisher's policies. Please refer to any applicable terms of use of the publishe

\section{General rights}

Copyright for the publications made accessible via the Queen's University Belfast Research Portal is retained by the author(s) and / or other copyright owners and it is a condition of accessing these publications that users recognise and abide by the legal requirements associated with these rights.

Take down policy

The Research Portal is Queen's institutional repository that provides access to Queen's research output. Every effort has been made to ensure that content in the Research Portal does not infringe any person's rights, or applicable UK laws. If you discover content in the Research Portal that you believe breaches copyright or violates any law, please contact openaccess@qub.ac.uk. 


\section{Bearing Witness to Child Abuse and Trauma in Pilar Acevedo's Multimedia ‘Fragmentos’ Exhibition}

Sarah E. L. Bowskill

Queen's University Belfast

Department of Spanish \& Portuguese

University Square

Queen's University Belfast

Belfast

BT7 1NN

Tel. +44 (0)289097 1141

Emails.bowskill@qub.ac.uk

Acknowledgements: I would like to thank Pilar Acevedo for permission to use images of her work in this article and Dr Jane Lavery and the Editor, Professor Jo Evans, for their generous feedback in the preparation of this article. 


\section{Abstract}

This is the first academic study of the artist Pilar Acevedo (born in Mexico and raised in Chicago), and more specifically, of her 'Fragmentos' exhibition at the National Museum of Mexican Art, Chicago (2013-14). It proposes that Acevedo's art tackles the challenge of bearing witness to the physical and psychological effects of child abuse in ways that help us to move beyond existing concerns within trauma theory that art which uses shocking images is not effective neither as art nor as a call to action. This article identifies the strategies Acevedo employs to encourage the viewer to participate actively in the construction of meaning whilst avoiding turning trauma into a spectacle that makes us turn away or feeds our voyeuristic fascination with pain. The techniques foregrounded include: firstly, the use of fragmented dolls as signifiers that draw on, but also depart from, the work of Hans Bellmer and Cindy Sherman and the traditions of surrealism and abject art. Secondly, a multimedia and intermedia approach that opens up new ways of seeing and experiencing art whereby the viewer is invited to piece together the fragmented narratives in a way that reflects the disruption of memory by trauma, and the work of psychoanalysis.

Keywords: Pilar Acevedo, Mexican American Art, Child Abuse in Art, Bearing Witness, Dolls in Art, Trauma, Abject, Multimedia

Tweetable Abstract: Analysis of Mexican American artist Pilar Acevedo's use of multimedia and avoidance of shock tactics to bear witness to child abuse

@BowskillSarah 
Shocking images are one way for artists to bear witness to trauma and inspire audiences to action. Yet the effectiveness of such images, both as art and as a means to inspire ethical action, has been brought into question. John Berger notes that violent war photographs can be 'arresting'. ${ }^{1}$ Looking at them, he writes that 'the moment of the other's suffering engulfs us' ${ }^{2}$ However, Berger continues to argue that the way in which these photographs capture and isolate the moment make it exceptional and therefore easier to disregard. ${ }^{3}$ Susan Sontag notes the potential of shocking images 'to accuse and possibly alter conduct'. ${ }^{4}$ Yet, she continues: 'one can become habituated to the horror of certain images'. Jane Kilby raises a still more problematic issue in relation to voyeurism, when she suggests that: 'we are all excited by the prospect of looking at expressions of pain'. 6 This fascination with the pain of others, she argues in her co-authored book on trauma culture, has fed an explosion of so called 'misery lit' and endless chat shows featuring the victims of abuse. ${ }^{7}$ Finally, Jacques Rancière suggests that contemplating images of suffering causes us to 'suspend any aesthetic appreciation' making the work less effective as art. $^{8}$ Taking into account these questions about the effectiveness of artistic representations of trauma, this article explores the way the visual artist Pilar Acevedo takes up this challenge by deliberately avoiding shocking or 'arresting' images and it proposes that Acevedo's art is significant because it enhances our appreciation of the way art may bear witness to trauma and engage audiences without turning trauma into a spectacle that feeds our voyeurism. Of particular interest will be her preference for images which, to use Hans Belting's phrase, 'bring the event into iconic presence' rather than providing documentary proof, her use of signifiers and colour as a semiotic code, her avoidance of shock tactics or techniques that might erase the child's experience or objectify the female child, even while she draws on the traditions of surrealist and abject art, and, finally, her innovative multimedia and intermedia approach. ${ }^{9}$

\footnotetext{
${ }^{1}$ John Berger, About Looking (London: Writers and Readers Publishing Cooperative, 1980), 38.

${ }^{2}$ Berger, About Looking, 38.

${ }^{3}$ Berger, About Looking, 38.

${ }^{4}$ Susan Sontag, Regarding the Pain of Others (London: Penguin, 2003$), 72$.

${ }^{5}$ Sontag, Regarding..., 72-73.

${ }^{6}$ Jane Kilby, Violence and the Cultural Politics of Trauma (Edinburgh: Edinburgh University Press, 2007$), 75$.

${ }^{7}$ On the public fascination with trauma see Kilby, Violence and Anne Rothe, Popular Trauma Culture: Selling the pain of others in the mass media (New Brunswick: Rutgers University Press, 2011).

${ }^{8}$ Jacques Rancière, The Future of the Image (London: Verso, 2009), 26.

${ }^{9}$ Frances Guerin and Roger Hallas, 'Introduction' in Trauma, Memory and Visual Culture, ed. Frances Guerin and Roger Hallas (London: Wallflower Press, 2007), 1-20, 12. Hans Belting explains that 'Iconic presence is
} 
Shalini Puri has referred to the Holocaust and New World slavery as 'the two paradigmatic models of trauma', and to these we might now add, the bombing of the Twin Towers in $9 / 11 .{ }^{10}$ Puri has noted how this traditional focus may obscure other experiences such as the Grenadian revolution about which she writes. Acevedo, however, moves away from such paradigmatic moments to tackle the trauma of child abuse in a way which also goes 'beyond privileging the individual as the site of trauma'. ${ }^{11}$ Kilby argues that, particularly when it comes to understanding cultural representations of sexual violence, one of the problems with contemporary trauma theory is that it 'repeats the moral logic of identity politics, and in so doing works within a framework established by liberal individualism'. ${ }^{12}$ It is essential, Kilby argues, to move beyond this focus on the individual if we are to tackle child abuse on a social and political level and I propose that Acevedo's work provides one example of how this may be achieved. ${ }^{13}$

In taking up the role of witness and bearing witness to child abuse through her art, Acevedo enters hotly contested debates about who should bear witness as well as what should and should not be represented. While Frances Guerin and Roger Hallas note that many critics have insisted on 'the radical limitations and aporia of visual representation in the face of historical trauma' they urge us to move beyond this debate and Jacques Rancière has pointed

presence in and as a picture. The physical presence of a picture in our world refers to the symbolic presence which it depicts. Similar to body and voice - and different from writing - the picture involves a representation which produces an impression of presence'. 'Iconic Presence. Images in Religious Tradition', Material Religion 12:2 (2016) 235-237.

${ }^{10}$ Shalini Puri, 'Finding the Field: Notes on Caribbean Cultural Criticism, Area Studies, and the Forms of Engagement', in Theorizing Fieldwork in the Humanities, ed. S.Puri and D.A.Castillo (New York: Palgrave Macmillan, 2016), 29-49, 41. 'Finding', 41. The following are just a few recent examples of studies on the holocaust and 9/11 from the field of trauma and memory studies some of which have been chosen to illustrate the new directions in the field: Victoria Aarons and Alan Berger, Third-Generation Holocaust Representation: Trauma, History and Memory (Evanston: Northwestern University Press, 2017), Lucy Bond, Frames of Memory after 9/11: Culture, Criticism, Politics and Law (London: Palgrave, 2015), Katharina Dorin, A Poetics of Trauma after 9/11: Representing Trauma in a Digitized Present (London: Routledge, 2012), Marianne Hirsch, The Generation of Postmemory: Writing and Visual Culture after the Holocaust (New York: Columbia University Press, 2012) Dominick LaCapra, Representing the Holocaust: History, Theory, Trauma (Ithaca: Cornell University Press, 2016), Dominick LaCapra, History and Memory After Auschwitz: Conspiracy Cultures from Outerspace to Cyberspace (Ithaca: Cornell University Press, 2014), Dori Laub and Andreas Hamburger, Psychoanalysis and Holocaust Testimony: Unwanted Memories of Social Trauma (London: Routledge, 2017), Paul Petrovic ed. Representing 9/11: Trauma, Ideology, and Nationalism in Literature, Film and Television (Lanham: Roman and Littlefield, 2011).

${ }^{11}$ Kilby, Violence, 5.

12 Kilby, Violence, 4.

${ }^{13}$ Kilby, Violence, 4. 
out 'Nothing is unrepresentable as a property of the event. There are simply choices'. ${ }^{14}$ The essential - and problematic - role of the 'witness' in bringing the testimony of the survivornarrator into being is outlined by Dori Laub. Laub is specifically interested in listening as an act of bearing witness but his remarks are also valid, I shall argue below, for Acevedo's visual approach:

In fact, the listener (or the interviewer) becomes the $[\ldots]$ witness before the narrator does. To a certain extent, the interviewer-listener takes on the responsibility for bearing witness that previously the narrator felt he bore alone, and therefore could not carry out. It is the encounter and the coming together between the survivor and the listener, which makes possible something like a repossession of the act of witnessing. ${ }^{15}$

Cathy Caruth also highlights the centrality of 'listening to the address of another, an address that remains enigmatic yet demands a listening and a response' in the process of bearing witness. ${ }^{16}$ Similarly, Guerin and Hallas have noted that the act of bearing witness requires 'an other, a listener, who consequently functions as a witness to the original witness'. ${ }^{17}$ Guerin and Hallas further assert that the capacity for bearing witness to trauma is not limited to firsthand witnesses because the listener-witness assumes responsibility to function as a witness to the original witness 'to perpetuate the imperative to bear witness to the historical trauma for the sake of collective memory'. ${ }^{18}$ Writing about the inspiration for her work, Acevedo states: 'Few of those memories are mine. Most are of other women who have recounted events of their unfortunate childhoods' ${ }^{19}$ The analysis that follows, therefore, outlines the techniques Acevedo uses to bear witness through her artwork in such a way that has the potential to produce new viewer-witnesses capable and willing to continue the process of bearing witness.

Acevedo's growing stature is evidenced by her first solo exhibition, 'Fragmentos' (National Museum of Mexican Art in Chicago, 26 December 2013 - 13 July 2014), and her

\footnotetext{
${ }^{14}$ Guerin and Hallas, 'Introduction' 4; Rancière, The Future of the Image, 129.

${ }^{15}$ Dori Laub, 'Truth and Testimony: The Process and The Struggle' in Trauma. Explorations in Memory ed. Cathy Caruth (London: Johns Hopkins University Press, 1995), 61-75, 69.

${ }^{16}$ Cathy Caruth, Unclaimed Experience. Trauma, Narrative, and History (London: Johns Hopkins University Press, 1996), 9.

${ }^{17}$ Guerin and Hallas, 'Introduction', 10.

${ }^{18}$ Guerin and Hallas, 'Introduction', 11.

${ }^{19}$ Pilar Acevedo 'Recent Work'.
} 
work has now been added to the permanent collection of the National Museum of Mexican Art, yet she has received no academic attention to date, so I shall provide a brief summary of her work to date before moving on to examine 'Fragmentos' in more detail. ${ }^{20}$ Born in Mexico and raised near Chicago, Illinois, Acevedo is a graduate of the Art Institute of Chicago, Santa Monica College and the Universidad Nacional Autónoma de México (UNAM). She gained recognition from local galleries in Illinois and, prior to 'Fragmentos', her work had been included in a number of group exhibitions across the United States. ${ }^{21}$ Acevedo employs a range of art forms from traditional oil painting to collage, mixed media assemblage and video art. She combines 'classical painting and drawing with sculpture and found objects, often employing vintage photographs, dolls, pieces of dolls and other toys, and assorted symbols of remembrance, religion, and a shadowed Mexican childhood'. ${ }^{22}$ Childhood is a major theme in her art and she writes that she is particularly interested in 'children's thoughts - their perceptions and fears - the idea of how situations like death or abuse can mean a loss of childhood'. ${ }^{23}$

During the 'Fragmentos' exhibit, the Chicago Broadcasting Service (CBS) identified her as one of the best visual artists in Chicago. ${ }^{24}$ Another favourable review of 'Fragmentos' was published in an online magazine for the Mexican community in Chicago called El BeiSMan. ${ }^{25}$ Since 2011, Acevedo has also been an active blogger and occasional poet. Her website www.pilaracevedo.com hosts her blog and provides a window for her artwork. ${ }^{26} \mathrm{Her}$ blog posts, written in English, include entries about her creative process, sources of

\footnotetext{
${ }^{20}$ Curated by Dolores Mercado this exhibition in the one-room Kraft Gallery included the following artworks all of which have titles in English and Spanish: Daddy's Little Trophies / Los pequeños trofeos de papá (mixed media assemblage, 2013), Yellow Cat/ Gato amarillo (oil on canvas, 2013), Lily: Queen of the Universe / Lily: Reina del universo (oil on canvas, 2007), Still Wish You Were Here / Como deseo que estuvieras aquí (oil on canvas, 2013), Plum Girl / Niña ciruela (oil on wood panel, 2013), Spider Princess / Princesa araña (oil on canvas, 2013), Untitled (2013), Monkey Love / Amor de mono (oil on canvas, 2013), I See Red / Yo veo rojo (oil on canvas, mixed media, 2013), Birthday / Cumpleaños (no date), 2 untitled drawings of dolls (2013), Naughty (Assemblage) and the poem 'Naughty'. Heaven Bound / Hacia el cielo (assemblage, 2013), Intangible Sweetness/ Dulzura intangible (assemblage, 2011), A Childhood, Una infancia (assemblage, 2009). Images of the artworks listed above and of the exhibition can be seen on Acevedo's website: Pilar Acevedo, www.pilaracevedo.com [accessed 23 May 2016].

${ }^{21}$ Full details and a list of exhibitions at which Acevedo's work has been shown can be found at: Pilar Acevedo, 'About' http://www.pilaracevedo.com/about [accessed 25 May 2015].

${ }^{22}$ Pilar Acevedo, 'About'.

${ }^{23}$ Pilar Acevedo 'Recent Work' http://www.pilaracevedo.com/ [accessed 26 May 2015].

${ }^{24}$ CBS Chicago 'Best Visual Artists to See in Chicago' April 14 2014. http://chicago.cbslocal.com/toplists/best-visual-artists-to-see-in-chicago/ [accessed 25 May 2015].

${ }^{25}$ Roxyo Colette, 'The Dream World in Fragmentos: Pilar Acevedo', this was linked on Acevedo's blog and includes some of the biographical detail reproduced here.

http://www.elbeisman.com/article.php?action=read\&id=110 [accessed 28/8/2014].

${ }^{26}$ Pilar Acevedo, 'About' and 'Blog' http://www.pilaracevedo.com/blog [accessed 25 May 2015].
} 
inspiration, and praise for other artists as well as publicity for forthcoming exhibitions. Far from being a simple marketing tool, however, the website, and especially the blog, provides additional valuable insights into her work and should be considered part of her creative oeuvre. ${ }^{27}$ The website also provides details of Acevedo's activist work aimed at helping vulnerable children. Her Art Alternative initiative aimed to teach a group of 'at risk' children 'math, language arts, science, geography and history through the use of art' ${ }^{28}$ Thus, through her artwork and activism Acevedo acts as an advocate for children and for children's rights as well as bearing witness to abuse.

The artworks to be discussed here were all included in the 'Fragmentos' exhibition. The first section analyses 'Untitled', 'I See Red', 'Lily Queen of the Universe', 'Heaven Bound', 'Cumpleaños', 'Monkey Love' and 'Daddy's Little Trophies' focusing on the way Acevedo engages with the history of the representation of dolls in surrealist and abject art using the uncanny, not to cause us to retreat, or shudder, but to engage. It identifies the significance of her use of fragmented dolls and the colour red, among other signifiers, as part of a semiotic code that, I will argue, brings the physical experience of abuse into iconic presence' without causing the viewer to turn away in horror, as may occur with abject art. It also considers how Acevedo attempts to draw the viewer in without fostering a voyeuristic gaze (albeit recognising that there are no guarantees in relation to viewers' response). As Rancière reminds us, the viewer's response cannot be determined in advance because 'the spectator also acts ... She observes, selects, compares, interprets. She links what she sees to a host of other things that she has seen on other stages, in other kinds of place. She composes her own poem with the elements of the poem before her. She participates in the performance by refashioning it in her own way .... ${ }^{29}$ Thus, whilst this article identifies elements and techniques that may guide our interpretation and response, it remains alert to the fact that the role of the viewer in constructing meaning(s) cannot be overlooked.

The second part of the article analyses Acevedo's blog and the artworks 'She's Alive', 'Spider Princess' and 'Naughty' highlighting the extent to which the multimedia and intermedial approach reflects the fragmentation of memory caused by trauma and the role of

\footnotetext{
${ }^{27}$ Acevedo is by no means alone in being a multimedia artist who works across traditional and new media. Other notable Spanish American examples include Regina José Galindo (Guatemala), Eli Neira, (Chile), and Lorena Wolffer (Mexico) to name but a few.

${ }^{28}$ Pilar Acevedo, 'The Art Alternative: A Brainchild' http://www.pilaracevedo.com/the-art-alternative.html [accessed 14 August 2014].

${ }^{29}$ Jacques Rancière, The Emancipated Spectator (London: Verso, 2011), 13.
} 
psychoanalysis in the process of recovery. ${ }^{30}$ Although the role of psychoanalysis in recovering trauma has been questioned, notably in relation to false memory syndrome and the recovered memory movement, it remains an important point of reference for Acevedo and consequently for this article. ${ }^{31}$ This section also discusses the significance of multimedia and intermedia artwork for expanding interpretive horizons that implicate the viewer in the creation of meaning rather than just as a witness to meanings uncovered by the artist. Ultimately, this article proposes that that Acevedo's work opens up new ways of thinking about how art can represent and bear witness to trauma in new ways which have the potential to tackle issues on a social and political and not just an individual level.

\section{Fragmented Bodies}

Dolls, many of them fragmented, featured in eleven of the pieces exhibited in the exhibition. In 'Untitled', for example, a girl stands in front of a pile of broken dolls, 'I See Red' depicts a doll with no arms and 'Heaven Bound' features a doll's head with a body made up of a bird cage and sticks for arms. These artworks include elements that do not immediately seem to belong together as, for example, in 'Cumpleaños' which evokes a familiar scene of a dollchild and a birthday cake with candles but turns it into a nightmarish scenario through the presence of a predatory goblin figure reminiscent of Henry Fuseli’s The Nightmare (1781).

Fig. 1 From left to right: 'Heaven Bound', 'Untitled', 'Monkey Love', 'I See Red', 'Cumpleaños'

In the foreground, a doll stands bolt upright with her eyes wide open in terror looking straight at the viewer as if appealing for help as a naked red-orange goblin launches itself at her, arms outreached as if trying to strangle her. The ground on which the doll stands is red and the whole canvas, including the doll's dress, is tinged by a pink hue suggesting that the goblin's presence is everywhere. Here, as elsewhere, red is part of a semiotic code used by Acevedo to

\footnotetext{
${ }^{30}$ While multimedia can be used to refer to the use of different discrete media as well as to the combination of different media, intermedia refers to a particular kind of crossover 'between traditional media (such as painting and photography) and contemporary media (such as cinema, television, video, computer and other hypermedia)' Yvonne Spielmann, 'Synesthesia and Intersenses, Intermedia in Electronic Images', Leonardo, vol. 34:1 (2001), 55-61, 55. 'She's Alive' and 'Naughty' are good examples of Acevedo's use of intermedia, both of which are discussed later in this article.

${ }^{31}$ On false memory syndrome and recovered memory see, for example, Kilby, Violence..., Chapter 1; Rothe, Popular Trauma Culture..., Chapter 9 'Forging Child Abuse'; J. Woodiwiss, Contesting Stories of Childhood Sexual Abuse (London: Palgrave, 2009).
} 
suggest (premature) child sexualisation and the presence of blood. ${ }^{32}$ The red colour gives this particular painting a nightmarish aura. Yet no bodily fluids are actually represented. The way the goblin reaches for the terrified girl and the blood red-orange colour that seems to emanate from it, floods the image, points to him as the signifier for the girl's abuser. In the absence of any overt physical injury, the pink colour that stains the white dress hints at sexual abuse. Thus, Acevedo's art presents what Kilby terms a 'testimonial image' which 'is not complete because it requires the active engagement of the viewer'. ${ }^{33}$ Testimonial images are in contrast to 'confessional images' which, at least on the surface, 'demand nothing from the viewer'. ${ }^{34}$ 'Confessional' images, Kilby, argues, afford the viewer 'instant, if blinding, access to the horror it depicts' but may induce 'boredom' and so are less effective at fostering empathy and engagement than 'testimonial' art such as that produced by Acevedo, which relies on the viewer decoding the images to understand what s/he is seeing. ${ }^{35}$

Acevedo's use of dolls produces an encounter with the uncanny, which, according to Kristeva, is a mainspring for identification with the other. ${ }^{36}$ According to Freud, the experience of the uncanny is the result of being confronted by a familiar childhood object which is made strange because it is associated with happy memories, but in its mutilated and broken state evokes simultaneously positive and negative feelings and memories from childhood. ${ }^{37}$ This experience is made particularly acute in the juxtaposition of child/doll and birthday cake with the threatening presence of the goblin. While the title, 'Cumpleaños' evokes the celebration of a child's life the painting is dominated by dark colours linking the birthday with a moment of trauma that will persist in the child's memory. Following Julia Kristeva, it may be argued that the doll here, and in other artwork by Acevedo, stages an uncanny experience taking the viewer back to their own childhood and fostering a more

\footnotetext{
32 There is a considerable literature about colour symbolism, psychology and the role of colour in influencing viewer perceptions. Red, for example, has been related to enhancing perceptions of attractiveness in women, leading to increased aggression and giving sports teams wearing red a competitive advantage. For further reading on the colour red see: Spike Bucklow, Red: The Art and Science of a Colour (London: Reaktion, 2016) and Michel Pastoureau, Red. The History of a Color (New Haven: Yale University Press, 2017). On colour in art see, for example, the work of John Gage including Color and Meaning: Art, Science and Symbolism (London: Thames and Hudson, 1999). Colour is also a significant feature in fairy tales (the use of which, by Acevedo, will be discussed), as indicated in titles such as Little Red Riding Hood and Snow White. See: Francisco Vaz da Silva, 'Use of Colour in Fairy Tales', Marvels and Tales, vol. 21.2 (2002), 240-252.

${ }^{33}$ Kilby, Violence, 85.

${ }^{34}$ Kilby, Violence, 85.

${ }^{35}$ Kilby, Violence..., 85 and 90.

${ }^{36}$ Julia Kristeva, Powers of Horror: An Essay on Abjection translated by L.S.Roudiez (New York: Colombia University Press, 1982), 182-92.

${ }^{37}$ Freud, The Uncanny, Ebook (Kindle Edition) Chapter 2.
} 
compassionate identification with the victims of child abuse. According to Sigmund Freud, dolls are particularly prone to provoking uncanny feelings or sensations because they confuse the relationship between the animate and inanimate inviting us to return to the time when we did 'not distinguish at all sharply between living and lifeless objects' and when we were 'especially fond of treating [...] dolls like live people'. ${ }^{38}$ As well as noting the way in which dolls blur the distinction between human and non-human, Freud also suggested that dolls connect to childhood memories and, through the experience of the uncanny, to the return of the repressed. Thus, the goblin and the birthday cake can be seen to represent a return of the repressed in the girl-doll's memories of her past and so 'Cumpleaños' reminds us of the ways in which the memory of childhood trauma persists with potentially damaging consequences. Given that the meaning is unstable, however, these images could also confirm an abuser's view of children as dolls who can be played with at will.

This use of dolls extends a longstanding tradition of using broken dolls to express trauma in surrealist art. Acevedo draws on but also departs from this tradition in significant ways, ways which, I would argue, enable her to address some of the criticisms made about art that may erase or objectify women. ${ }^{39}$ Acevedo's work is informed by the legacy of surrealism but does not rely on shocking images such as the cutting of the eye at the beginning of Luis Buñuel and Salvador Dalí's classic surrealist film Un chien andalou (1929). Nevertheless, as can be seen, for example, in 'Plum Girl', it exploits, in a similar way, what Ranciere describes as the 'clash on the same surface of heterogeneous, if not conflicting, elements' that may 'account for the artistic and political success of collage and photomontage'. ${ }^{40}$ This strategy, Rancière notes, was used by the surrealists 'to express the reality of desire and dreams repressed under the prosaic character of bourgeois quotidian reality' and later by Marxists when it 'aimed to have a dual effect: an awareness of the hidden reality and a feeling of guilt about the denied reality'. ${ }^{41}$ To be successful, these techniques, which are taken up by Acevedo, rely not on voyeurism or repulsion but on attraction, fascination, and the viewer identifying with the doll, who is not presented as abject as in the surrealist tradition, and engaging with the multi-layered art to reveal this hidden reality.

\footnotetext{
${ }^{38}$ Freud, The Uncanny, Loc 211 of 607 . Chapter 2.

${ }^{39}$ On the criticisms levelled at surrealism from a feminist perspective see Natalya Lusty, Surrealism, Feminism, Psychoanalysis (Surrey: Ashgate, 2007).

${ }^{40}$ Rancière, The Emancipated Spectator, 26.

${ }^{41}$ Rancière, The Emancipated Spectator, 26 and 27.
} 
If, as I have argued, Acevedo's approach encourages identification with the victim (the doll) rather than with an attempt (on the part of the surrealist artist) to liberate ourselves from bourgeois convention, then we can also link the experience of viewing her work to the physical suffering and psychic legacies of abuse.. Malcolm Bowie suggests that the idea of the fragmented body (corps morcele) in Lacanian psychoanalytic theory was influenced by Hans Bellmer's surrealist photographic sequence Dolls in which adult broken dolls feature prominently. ${ }^{42}$ According to Lacan, even after the child has begun to perceive itself as a separate being with its own identity, the individual continues to be haunted by memories of the body seeming to be dismembered. Subsequently, the ego strives for complete wholeness but 'phantasies of dismemberment are a burden that all self-aware membered creatures bear' ${ }^{43}$ Thus, as will be discussed, by using fragmented dolls of the type associated with childhood, which promote identification with the other and are not overtly sexualised rather than mannequins Acevedo references the way in which sexual abuse shatters the victim's sense of identity at an early age in a way which will have a lasting legacy into adulthood as well as the physical injuries caused by abuse.

Writing about the effect of Bellmer's art on the viewer, Andrew Brink states:

For many viewers, Bellmer's hyper-sexualised and misogynistic doll images simply overwhelms any aesthetic response. [... It is impossible to fix on it with the surrender necessary to intensive seeing [...] No amount of sophisticated irony, or 'seen it all before' distancing can overcome basic human responses of the deepest unease in the presence of Bellmer's dolls and the other later hypersexualized and eviscerated 'created' objects'. ${ }^{4}$

Bellmer's images are examples of 'confessional images' which confront the viewer and threaten to cause what Barbara Creed has termed a 'crisis of viewing' which occurs when 'boundaries, designed to keep the abject at bay, threaten to collapse'. ${ }^{45}$ In contrast to Bellmer's shocking images and the later tradition of abject art, however, Acevedo does not confront viewers with disturbing, sexualised images with which they might engage voyeuristically or from which they might turn away. Rather, Acevedo's multi-layered work

\footnotetext{
42 Bowie, 215.

${ }^{43}$ Malcolm Bowie, Lacan (Cambridge, Mass. Harvard University Press, 1991), Bowie, 29.

${ }^{44}$ Andrew Brink, Desire and Avoidance in Art: Pablo Picasso, Hans Bellmer, and Joseph Cornell. Psychobiographical Studies with Attachment Theory (New York: Peter Lang, 2007), 78.

${ }^{45}$ Barbara Creed, The monstrous-feminine: Film, feminism and psychoanalysis (London: Routledge, 1993$), 29$.
} 
fascinates; because the 'story' behind the scene is not immediately apparent it entices the viewer to look more closely, to be drawn in as a witness to the story so that, when suggestions of abuse are revealed, it produces an unsettling feeling; the feeling of growing realisation, but not a visceral urge to look away.

As well as recalling the work of Bellmer, Acevedo's use of dolls also connects her to the work of Cindy Sherman including, for example, Sherman's 'Sex Pictures' series produced in the 1990s. The scene depicted in 'Untitled' recalls fairy tales in which children get lost in the woods, and it particularly brings to mind Sherman's 'Fairy Tales' (1985) series as well as Bellmer's mannequins in the woods. Neither Acevedo's 'Untitled' painting nor Sherman's series reference specifically identifiable fairy tales but both show "'emanations of irrational fears verging on terror, relics of childhood nightmares," personifying " the stuff of the unconscious itself"'" ${ }^{46}$ Sherman made her name using her own body in her artwork but the 'Fairy Tales' series was the first in which she used fake, plastic body parts. ${ }^{47}$ Acevedo consistently uses plastic dolls to stand in for girl children. The 'Untitled' painting is predominantly black, grey and white suggesting dark emotions and fears as well as a lack of hope. Indeed, the title of the painting underlines the fact that many instances of abuse are not acknowledged as victims remain silent or people look away allowing the perpetrators to continue and to go unpunished. Even the little girl in the foreground lacks colour. The only colour in the image comes from the girl's reflection in the mirror and the pile of broken doll limbs in the background both of which are a pink flesh colour. Using the same colour for the dolls and the reflection creates a visual link between the girl and the dolls which could be interpreted as suggesting that the girl fears that she too will be the victim of the kind of physical abuse already suffered by the dolls. The girl faces the viewer holding a mirror with her reflection in it even though it is pointed towards the viewer thus drawing the viewer into the image and inviting them to identify with the child. This girl, like the one in 'Cumpleaños' and those in other pieces by Acevedo, looks directly at us which is another technique the artist uses to engage the viewer who is drawn into the image by the girl's gaze and the mirror which connects signifier (fragmented dolls) and signified (the abused girl).

\footnotetext{
${ }^{46}$ Laura Mulvey on Sherman quoted in Jan-Ove Steihaug, 'Abject/informe/trauma: Discourses on the Body in American Art of the Nineties', ForArt (1995), 33 http://www.forart.no/steihaug/toc.html [accessed 23 March 2016].

${ }^{47}$ Skarstedt Gallery, 'Cindy Sherman. Fairy Tales - 1985. May 6 -July 12000 '

http://www.skarstedt.com/exhibitions/2000-05-06 cindy-sherman/\#/images/4/ [accessed 5 August 2015].
} 
Acevedo may draw on the work of Bellmer and Sherman but her dolls are aesthetically very different from the mannequins they used; Acevedo's are the child-like dolls which were first typically made of porcelain and later of plastic and which emerged as popular children's toys at the turn of the twentieth-century. The decision to use this type of doll, rather than a mannequin, re-enforces the connections to childhood, (virginal) purity and innocence and distances Acevedo's art from that of Bellmer and Sherman which references a supposedly abject adult female sexuality. By not presenting her (mostly female) dolls as abject, Acevedo's art represents a significant break with the tradition of abject art and criticism which identifies the feminine 'body as a primary site/sight of cultural disgust' ${ }^{48}$ Natalya Lusty has highlighted the problematic representation of women in the context of Surrealism and psychoanalysis, the legacies of which are evident in Acevedo's work. Lusty notes 'the simultaneous erasure and fantasy of woman as other' in both schools of thought. ${ }^{49}$ Lusty identifies a progression between Bellmer and Sherman in the way that Sherman's 'Sex Pictures' series engages with and challenges the representation of the female body in Bellmer's art unsettling 'a Surrealist violation of the female body' but still utilizing 'the affective registers of 'shock' in Bellmer's own work'. ${ }^{50}$ Acevedo can be seen to go one step further in the way in which she substitutes mannequins associated with adult sexuality with dolls which are linked to childhood, draws on the legacies of surrealism, psychoanalysis, and, as will be seen abject art, but does not rely on shock.

Tracing the development of the mixed media oil painting 'I See Red' provides ample evidence of the way in which Acevedo resists objectifying the female doll-child as an object of desire as well as how she departs from abject art yet also uses similar alienation techniques to engage our compassion and our consciousness, rather than our voyeuristic attraction towards the abject. In the early drafts of the painting the doll was naked but not broken. In the final version the doll is clothed but her arms are missing. In this way, the final painting bears witness to the physical effects of abuse but, deviating from the tradition of abject art, avoids shocking the viewer by using dolls as signifiers for girls and the colour red to signify blood and child sexualisation rather than displaying the naked body which might invite a voyeuristic gaze.

\footnotetext{
${ }^{48}$ For a discussion of the problems of abject art and criticism see: Imogen Tyler, 'Against Abjection', Feminist Theory April 10:1 (2009) 77-98, 81.

${ }^{49}$ Lusty, Surrealism, 14.

${ }^{50}$ Lusty, Surrealism, 6.
} 
Rooted in the Surrealist movement and Georges Bataille's concept of the formless (l'informe), and drawing on the legacy of the aforementioned Hans Bellmer, abject art came to the fore in American art of the 1990s. Influenced by Julia Kristeva's Powers of Horror: An Essay on Abjection (1980, translated into English in 1982), abject art confronted the viewer with representations of sexualised, broken and fragmented bodies and bodily fluids which produced a sense of disgust and a desire to look away, but that also fascinated. Abject art aimed to "trigger [...] the affect around disgust, the feeling of engaging the abject". ${ }^{51}$ While the curators' selection of works for the first exhibition of abject art 'oscillated between degrees of referentiality, from abjection's suggested presence to its direct citation' subsequently, 'abject art' has tended to be that which goes beyond suggestion, for example that which contains actual bodily products. ${ }^{52}$ Within a Kristevan framework, however, the sense of horror that abjection provokes is accompanied by sense of fascination that draws the viewer in to question the performance and understand what $\mathrm{s} /$ he is seeing. ${ }^{53}$ Furthermore, according to Kristeva, the abject is associated with 'showing'. ${ }^{54}$ She notes, for example, that the actual encounter with a dead body does not produce the same feeling as a signifier of death. ${ }^{55}$ In other words, seeing a dead body does not provoke the same feelings as seeing a flat encephalograph. ${ }^{56}$ Showing the abject, she argues, causes the beholder to faint whereas signifying causes the beholder to 'understand, react, or accept' ${ }^{57}$ Signifying, therefore, is the more effective tool for engaging the audience rather than the 'showing' that is characteristic of abject art.

Signifying is an important strategy in 'I See Red' and in the evolution of this image we can trace how Acevedo deliberately avoids the strategies of abject art and mitigates the potential for engaging a voyeuristic gaze on the part of the viewer. As is often the case in Acevedo's work, the title provides an important clue as to how we might interpret the image. 'I See Red' mockingly alludes to the clichéd defence of abusers that they 'saw red' and in a moment of anger violently lashed out as well as to the visible colour of the red shoes the girl-doll wears.

\footnotetext{
${ }^{51}$ Joseph Henry, 'The Suffering Body of 1993: Whatever happened to the "Abject"?' Part I and Part II, MOMUS April 272015 http://momus.ca/the-suffering-body-of-1993-whatever-happened-to-the-abject/ and http://momus.ca/the-suffering-body-of-1993-whatever-happened-to-the-abject-part-ii/ [accessed 4 April 2016]

${ }_{52}^{52}$ Henry, 'The Suffering Body of 1993'.

${ }^{53}$ Kristeva, Powers, 2.

${ }^{54}$ Kristeva, Powers, 3.

${ }^{55}$ Kristeva, Powers, 3.

${ }^{56}$ Kristeva, Powers, 3.

${ }^{57}$ Kristeva, Powers, 4 and 3.
} 
The shoes protrude from the canvas in an eye catching way to the extent that an online reviewer of the exhibition described 'I See Red' as: 'la pieza que me cautivó desde que entré a la sala'. The 'captivating' quality of the piece, its striking use of colour and the positioning of the doll, whose legs are spread wide apart to draw the viewer's gaze. In the gallery, alongside the finished mixed media version of 'I See Red', an earlier sketch was displayed showing a naked doll, with arms, sitting with her legs wide apart. In her blog Acevedo shares other sketches which reveal the evolution of the image from a naked doll whose stomach covers the pubic region, to a doll with the pubic region revealed although, because this is a plastic doll, there are no sexual organs only a smooth plastic surface. In the final artwork, the girl still sits in the same position but she is wearing a dress, which covers her public region, and red shoes. The girl no longer has arms and the shoes are foregrounded as they protrude from the image. In each iteration, the doll's posture draws the viewer's gaze is inevitably and voyeuristically towards the pubic area. Not only are the girl-dolls encoded in terms of penetration by the implied male 'member', but they are also presented as the locus of (paedophilic) sexual brutality. In the final artwork, however, the pubic area is completely covered by the white dress frustrating, at least to some extent, a voyeuristic gaze. Ultimately then, the viewer of 'I See Red' is invited to confuse the doll in the image with a real child in order to highlight issues of child abuse, but the use of a doll and the modifications made over the course of the series point to a deliberate attempt not to use the direct shock tactics of abject art which might either produce a crisis of viewing or provide satisfaction for a voyeuristic gaze.

The viewer may first be struck by the haptic and tactile quality of the red shoes which protrude from the painting underlineing the association with childhood, dressing up, and the childish urge to perceive through touch that is, of course, prohibited in an art gallery. The provocation of the desire to touch acts as another way of encouraging the viewer to engage with the artwork. Once again, however, there is a gradual realization that the childhood that is represented has been marked by the experience of abuse. The girl-doll's missing arms are the first sign of abuse and in her blog Acevedo explains that in earlier versions of the artwork the doll's white dress, signifying purity, was blood-stained from her arm injuries. ${ }^{58}$ The images once again use colour as a semiotic code but the red stain on the dress is absent from the final

\footnotetext{
${ }^{58}$ Pilar Acevedo, 'Work in Progress' http://www.pilaracevedo.com/blog/category/i\%20see\%20red [accessed 28/8/2014].
} 
painting having been replaced by striking red stiletto shoes. Even more so than in 'Cumpleaños', the colour red here is connected not only to blood but also to the premature sexualisation of the child by the abuser. Stilleto shoes could be considered a symbol of ostentatious, even provocative femininity and red is associated with passion as well as blood. However, the doll's shoes are too big for her and so hint at the way in which children dress up in order to pretend to be adults. The child's costume could be seen as evidence of sexual maturity, but such an interpretation is undermined by the fact that the shoes are too big. In addition, the writing on the soles of the shoes highlights the threat to the doll-child's innocence and undermines the potentially voyeuristic gaze ${ }^{59}$ On the sole of the doll's right shoe the verb 'huir' is conjugated and on the left shoe are synonyms in English and Spanish. These words underscore the girl-doll's rejection of her sexualisation by her abuser and her attempts to run away even when hindered by ill-fitting shoes. Finally, 'I See Red', challenges the potentially voyeuristic gaze via the doll's gaze. Acevedo explains: 'The detached gaze was her only way of escaping since she could not run in high heels, nor did she have hands and arms with which to protect herself' ${ }^{60}$ Once again, the doll stares blankly out of the canvas refuting the voyeuristic gaze whilst inviting the viewer to identify with her plight

Dressing up and a different kind of blanked-out gaze also feature in the painting 'Lily Queen of the Universe'. Whereas dolls are used to put the distressing subject of child abuse at a 'safe' distance, the celebratory image of 'Lily' does not need to be mediated in this way. 'Lily' takes on the conventions of royal portraiture to depict a girl seated on a multi-coloured chair-throne in a pink and white dress with a sparkling crown on her head holding a wand with a yellow star. She has a colourful beaded necklace and matching bracelet and pink sunglasses. The painting uses bright colours and the style recalls the glossy images of children's books and films. Writing on her blog Acevedo states:

'My art often speaks to subconscious fears that stem from the uncertainties of childhood, from a childlike perspective. However Lily: Queen of the Universe, illustrates a child's inner strength, spunk, and incredible ability to imagine and believe her fantasy'. ${ }^{61}$

\footnotetext{
${ }^{59}$ A close up of the sole can be seen among the images in the blog post Pilar Acevedo, 'My Solo Exhibit at the National Museum of Mexican Art http://www.pilaracevedo.com/blog/category/fragmentos\%20works \%20by\%20pilar\%20acevedo3b063236b9 [accessed 11/4/17] and Pilar Acevedo, 'Now in the National Museum of Mexican Art's Private Collection' http://www.pilaracevedo.com/blog/archives/07-2014 [accessed 11/4/17].

${ }^{60}$ Pilar Acevedo, 'I See Red' http://www.pilaracevedo.com/blog/category/i\%20see\%20red [accessed 11/4/17].

${ }^{61}$ Pilar Acevedo, 'Lily: Queen of the Universe'. http://www.pilaracevedo.com/blog [accessed 14 August 2014$]$.
} 
According to Acevedo, the painting aimed to capture childhood innocence, the playfulness of dressing up and the freedom to imagine being in control of your own destiny. Nonetheless, albeit unintentionally, the image betrays very little emotion largely because the child's eyes are covered by the sunglasses and her lips are not obviously smiling. On the one hand, this could, as Acevedo suggests connote a child 'reigning' over her own fantasy world. However, these clothes also speak of a consumer culture that encourages young girls to wear pink dresses and aspire to marrying into royalty rather than to dream of being teachers or astronauts. The dress further calls to mind the type worn at modern quinceañera celebrations to mark the transition from childhood to early adulthood and availability for marriage, a social contract that would now deemed inappropriate at the age of fifteen. The red tint on the girl's lips and the dress, reference a burgeoning sexuality over which, Acevedo's comments suggest the girl will have some control and from which she will not have to flee as in 'I See Red'. Nevertheless, 'Lily' reminds us that while artists may try to find techniques to engage viewers and suggest ways of interpreting their work, as Acevedo often does on her blog, meanings cannot be fixed by them. Her contemporary and multimedia work, unlike that of more traditional surrealist and abject art, emphasizes the 'openness' of the imagery rather than inviting us to focus compulsively and voyeuristically on one intensely highlighted and abject 'fragment' such as the fetishized stiletto in film noir. This openness which, as will be seen, extends across different media, is a technique with the potential to promote engagement but, as ever, there is no guarantee as to the way a viewer may respond.

Acevedo rejects the confrontational aspect of abject art, which insists on showing actual bodily fluids or images of dead bodies in favour of using the gaze and colour as semiotic codes, along with the symbols and signifiers associated with the dolls, the goblin and the red shoes. She makes this choice to mitigate the potential for the viewer to avert their gaze, replicating the tendency to ignore, to look away from, the on-going abuse of children today. The fact that people turn away from child abuse is alluded to, as we have seen in the 'Untitled' painting as well as in the painting 'Monkey Love'. In this painting a toy monkey looms over a doll wearing the white dress to signify innocence that we have seen in 'I See Red' and 'Cumpleaños'. The shadow he casts on the wall behind and the way in which his face is hidden by his hat so that only a menacing grin is visible suggest that he is a threatening presence. In the background are shelves which hold other toys including a pair of figurines, one male and one female, standing next to one another. Far from presenting a scenario in which the monkey looks lovingly at the doll, as the title might suggest, the 
monkey, which represents the doll-child's abuser, could be interpreted as giving in to animal instincts. 'Monkey love' is a slang term for animalistic sex and so points to an inappropriate sexual desire on the part of the monkey for the sleeping doll. ${ }^{62}$ The figurines in the background, one looking directly outwards and the other turning away, represent those who turn away and do nothing when they witness child abuse. Through the use of signifiers, which require decoding by the viewer, Acevedo turns what could first appear to be an innocent scene composed of children's toys into a disturbing representation of unreported child abuse, while the use of toys rather than people and the way the doll is fully clothed mitigate the possibilities of engaging with this image voyeuristically.

The mixed media assemblage 'Daddy's Little Trophies' likewise references the silence surrounding child abuse. It shows a clenched fist holding three severed heads on a string. The fist is red, signifying blood, and alluding to the abuse perpetrated by that hand. The knuckles are ironically marked XOXO, which is the popular text symbol for hugs and kisses although it is clear that the children have received only abusive 'love' from this hand. Acevedo writes that this piece 'was inspired by a man who deluded himself into believing that he was a good father, yet he physically and sexually abused his children [...] As children, they accused him of abuse, but later recanted their accusations, as victims of abuse often do. Later, as psychologically damaged adults, they lauded him as a saint' ${ }^{63}$ Acevedo can thus be seen to use her art, and her writing to bear witness to the complexity of the (anonymised) stories and memories of child abuse about which she has read or heard. ${ }^{64}$ As noted above, Acevedo draws on the memories of others more than her own experience. Yet here, as in the rest of her art, the individual is not prioritised in the final artwork exhibited in the gallery. Her paintings do not put the spotlight on specific cases, names are not included and surrealism (the use of dolls) is preferred over realism. In addition, that fact that the dolls all look alike in physical appearance and dress is important. This move away from individuation, is also an important aspect of her attempt to narrow the options for the voyeuristic gaze. The non-voyeuristic viewer is also urged, by this use of almost undifferentiated dolls, not to succumb to a passive empathy with the individual victim of child abuse, but to consider engage with the need to tackle child abuse on a social and political level. On the other hand, the fact that Acevedo draws on the traumatic experiences of others leaves her open to

\footnotetext{
62 'Monkey Love' http://www.urbandictionary.com/define.php?term=monkey+love [accessed 20 August 2015].

${ }^{63}$ Pilar Acevedo 'Daddy’s Little Trophies' http://www.pilaracevedo.com/blog/archives/06-2013 [accessed 4 May 2017].

${ }^{64}$ See for example the post 'Inspiration' about the assemblage Intangible Sweetness: Pilar Acevedo, 'Inspiration' http://www.pilaracevedo.com/blog/category/creative-process [accessed 11/4/17].
} 
accusations of appropriating the pain and suffering of others and one might also ask if she is really equipped to represent something she may not have experienced. It must be remembered, however, that even in the case of first hand witnesses expressing traumatic experiences via aesthetic practices, mediation is still involved. Moreover, the techniques Acevedo uses mean that her art is less likely to be drawn into potentially challenging and damaging questions about the 'truth' of what is represented, which have been the focus of many recent debates and controversies associated with the recovered memory movement. ${ }^{65}$

The title 'Daddy's Little Trophies' calls to mind the 'trophy of limbs' which Lacan identifies as an experience of the fragmented body and so, like Acevedo's other assemblage, 'Heaven Bound', it references the way in which abuse works to deprive victims of their sense of self.

Fig. 3 Detail of 'Heaven Bound'

According to the blog posts entitled 'Heaven Bound' and 'Art Inspires More Art' from November 2012 and September 2013 the assemblage 'Heaven Bound' was inspired by African American poet Paul Laurence Dunbar's poem 'Sympathy' (1899). In the poem the speaker identifies with a caged bird, who continues to struggle against confinement even when it is futile and is physically harmful to do so. The lines written on the cage of the installation echo the ending of Dunbar's poem in which the bird's song

is not a carol of joy or glee,

But a prayer that he sends from his heart's deep core But a plea, that upward to Heaven he flings-- 66

Acevedo's assemblage picks up the theme of struggle against an oppressor. However, where the poem concludes with the bird's song for freedom, the installation, which shows birds in flight from the cage, implies that this freedom is achieved not through physical release via the cage door, which remains closed, but through death. The idea of death as freedom is reinforced by the writing on the cage which states: 'Oppressed by the stain of this thing called life my spirit reaches heaven bound in song' suggesting that although the doll-child's body is

\footnotetext{
${ }^{65}$ For a discussion of debates and controversies surrounding the recovered memory movement, see Kilby, Violence, Chapter 1.

${ }^{66}$ Quoted on Pilar Acevedo, 'Art Inspires More Art', http://www.pilaracevedo.com/blog/art-inspires-more-art [accessed 13 August 2014].
} 
physically trapped her spirit, represented by the birds, is free. ${ }^{67}$ In Dunbar's poem the emphasis is on the need to continue the struggle, even though it seems futile, but 'Heaven Bound' makes the ending bittersweet as the doll-child seems to have found some liberation albeit not in this life. The difference between the caged birds and the child here also reminds us that children are more dependent on the care of their parent-keepers and consequently more vulnerable to abuse. Returning to Daddy's Little Trophies', however, the victims have found no such release and are presented as being unable to reassert their identity as the eyes and mouth of each of the victims are sewn shut with string pointing to the way in which they are rendered voiceless by their experience of abuse.

\section{Fragmented Minds}

The fragmented dolls which feature so heavily in Acevedo's art highlight the more immediate physical effects of child abuse but, as is evident in 'Daddy's Little Trophies' and 'Cumpleaños', her art also draws attention to the more long-term mental damage. Indeed, as well as representing fragmentation in the content of her work, the form of that work is also fragmented in a way that calls upon the viewer to trace meanings across different media. This method of dispersing meanings across different media also places the viewer in a position akin to that of a psychoanalyst whose role is to recover what has been forgotten as a result of trauma from 'the fragments of memories, from the associations and from the behaviour of the subject of the analysis'. ${ }^{68}$ By participating in the process of (re-) constructing the fragments the viewer, like the psychoanalyst, becomes an active participant and witness to the trauma.

The title of the exhibition, 'Fragmentos', therefore not only references Lacan's concept of the fragmented body and the presence of fragmented dolls, but also the fact that trauma may cause victims to forget, partially to remember or to repress their experience. The aim of psychoanalysis is to 'bring the evidence materialized by the unconscious testimony into the realm of cognition', or, in other words, to piece together the fragments of memory. ${ }^{69}$ Roger Kennedy describes the incompleteness of the memories recovered as a result of psychoanalysis as follows:

\footnotetext{
${ }^{67}$ These words are written around the cage in such a way as it is not immediately clear where they start and end. The intended order which is replicated here can be found on the blog Pilar Acevedo, 'Heaven Bound' http://www.pilaracevedo.com/blog/previous/3 [accessed 13 August 2014].

${ }^{68}$ Sigmund Freud, 'Constructions in Analysis' in The Standard Edition of the Complete Psychological Works of Sigmund Freud, ed. by James Strachey, 24 vols (London: Hogarth Press, 1964), 23, 257-269, 259.

${ }^{69}$ Shoshana Felman, Testimony: Crises of Witnessing in Literature, Psychoanalysis and History (New York: Routledge, 1992), 16.
} 
The kind of historical material with which the psychoanalyst is concerned seems at first sight rather strange, as it consists of multi-layered fragments of memory, odd bits of debris from the past, dream elements, gaping absences, convincing and also unconvincing stories, a history of discontinuities and unresolved questions, of traumas, things unsaid, and memories actively destroyed. ${ }^{70}$

Given that the narratives produced by victims of trauma (through psychoanalysis or otherwise) are fragmented and that trauma challenges representation, Judith Butler has argued that 'psychoanalysis will have to relearn the skill of reading broken narratives'. ${ }^{71}$ Acevedo's multimedial and intermedial approach disperses meaning in a way that aims to mimic the psychological effects of abuse, and to encourage the viewer to perceive meanings from a deliberately 'broken' narrative that encourages identification and interpretation, rather than a voyeuristic gaze.

Acevedo works across different media by supplementing her art with content on her blog and website and by incorporating sound and the written word into her assemblages. She uses her blog to introduce her work to new audiences and to enhance the viewer's experience of her artwork. In her blog she places photographs of her paintings, collages and assemblages alongside poems, some by her and some not, and (very) short stories, which could be considered examples of what has been termed in Spanish mini-relatos or mini-cuentos. ${ }^{72}$ These texts often 'tell the story behind' the image. The introductory text to the Chicago 'Fragmentos' exhibit, written by the curator Dolores Mercado, underscored the importance of narrative in Acevedo's work:

Narrative is a constant in the pictorial and three-dimensional work of Pilar Acevedo, making it difficult to separate one from the other. In every created work is a written story.

Thus, the written word and image, as well as form and content, are inextricably linked in Acevedo's oeuvre.

\footnotetext{
${ }^{70}$ Roger Kennedy, 'Memory and the Unconscious', in Memory: Histories, Theories, Debates ed. Susannah Radstone and Bill Schwarz (New York: Fordham University Press, 2010), 179-97, 181 [emphasis added].

${ }^{71}$ Judith Butler, Undoing Gender (New York: Routledge, 2004), 155.

72 The form of writing defined as 'mini-relato' and 'mini-cuento' seems to be more common in Spanish language cultural production than in in English hence the use of the Spanish terms. For definitions of 'minirelatos' and 'mini-cuentos' see: 'Literatura Electrónica Hispánica', http://www.cervantesvirtual.com/bib/portal/literaturaelectronica/enlaces.html [accessed 4 June 2014].
} 
By rewarding sustained viewing and re-viewing in the gallery and online, Acevedo may be said to promote deeper engagement with the artwork so that the online image and gallery exhibit do not stand in for, but rather supplement, one other. Strategies evident in the oeuvre that aim to engage the spectator are particularly significant given that our experience of art 'is increasingly mediated by technology' and this 'hyper-visibility ... can transform a unique installation into a commodified image'. ${ }^{73}$ The viewer of Acevedo's work may be prompted to go to the website following a gallery visit or vice versa but the experience in each space will be different. In this way, Acevedo's work reminds us, to borrow Sarah Hromack's words, that 'it is crucial that we keep looking at and experiencing works of art in the real world' while she equally showcases the experiences new technologies can provide that our 'real world' experience cannot.

The installation, 'Heaven Bound', would go on feature in a video called 'She's Alive', exemplifying the way the multimedia approach invites the viewer to interpret and re-interpret works that may themselves be subject to on-going reinterpretation by the artist. The video was produced using still images of the installation set to Leonard Cohen's song Dance Me to the End of Love. The effect is haunting and creates a very different experience from the one of seeing 'Heaven Bound' in the gallery setting. The video was posted on her blog where Acevedo explains that it came about when she was viewing photographs of 'Heaven Bound' and in them 'she' appeared to be dancing. ${ }^{74}$ The change in the title from the installation to the video suggests an optimistic shift. The original iteration of this work suggests release from abuse was only possible in death, whereas its reiteration and the title of the video call to mind the children's story of Pinocchio, the wooden puppet who wanted to be a real boy and whose wish was granted. The lyrics of the song also seem to re-enforce the tale of wish-fulfilment as the singer, whom we imagine speaking to the living doll, wishes that the two of them, in love, will dance together forever. Our understanding of the video is altered again, however, if we read the quotation from Cohen, included in the blog, which explains that the inspiration for the song came from orchestras of concentration camp prisoners which were made to play while fellow prisoners were being killed. This quotation reasserts the idea from the assemblage that death may be a release from suffering or that the experience of abuse is like a living death. Interestingly, grappling with the challenges of bearing witness in art, Theodor Adorno also used the example of the concentration camp orchestras writing about 'the need

\footnotetext{
${ }^{73}$ Sarah Hromack quoted in 'The Museum Interface' by Sarah Hromack and Rob Giampietro. http://www.artinamericamagazine.com/news-features/magazine/the-museum-interface/ [accessed 25 May 2015].

${ }^{74}$ Pilar Acevedo, 'She’s Alive', http://www.pilaracevedo.com/blog/heaven-bound1) [accessed 6/8/14].
} 
to lend a voice to suffering' as well as the inadequacy of representations of human suffering. ${ }^{75}$ Acevedo does not cite Adorno directly, but her use of the song points directly to the challenge of bearing witness to child abuse and her awareness of its limitations. From there, the viewer familiar with Adorno's famous comment may reflect on the way that Acevedo's work tackles the challenge of representing of trauma even after Adorno's often misquoted and misunderstood claim that to write poetry after Auschwitz is barbaric or that it is impossible to write poetry after Auschwitz ${ }^{76}$

The blog entry 'The making of Spider Princess' further illustrates the close connection between image and text that is typical of Acevedo's work. ${ }^{77}$ When the painting 'Spider Princess' is viewed in conjunction with the short story new interpretations emerge as a result of the interaction between the media making it a good example of how Acevedo engages her audience by producing multimedia fragments which they can piece together.

Fig. 4 'Spider Princess'

In the blog the short story precedes the image of the painting setting up a frame of reference. The story reads:

As a result of a magic spell cast by the Grey Witch, the Spider Princess sprouted from a flower - part spider and part human. The king, her father, declared her the "Spider Princess" and gave her dominion over the grey people. Sadly, she did not understand nor love them because they were a heartless people - colorless and empty. So, one by one, she punished them for their acts of cruelty, hoping that they would change their ways, yet they did not. In fact, their hardheartedness worsened, and as time went on, she began to change little by little until finally one day, she became like them. ${ }^{78}$

\footnotetext{
${ }^{75}$ Adorno wrote: 'If thought is not measured by the extremity that eludes the concept, it is from the outset in the nature of the musical accompaniment with which the SS liked to drown out the screams of its victims'. Quoted in Shoshana Felman, Testimony. Crises of Witnessing in Literature, Psychoanalysis, and History (New York: Routledge, 1992), 34. This explanation of Adorno's argument draws on Jenny Edkins and Nick VaughanWilliams eds., Critical Theorists and International Relations (London: Routledge, 2009), 16.

${ }^{76}$ On the interpretation of Adorno's argument from which these (mis)quotations come see Klaus Hoffmann, 'Poetry After Auschwitz - Adorno's Dictum', German Life and Letters 58.2 (2005), 182-194.

${ }^{77}$ Pilar Acevedo, 'The Making of Spider Princess' http://www.pilaracevedo.com/blog/the-making-of-spiderprincess [accessed 4 June 2014].

78 Acevedo, 'The Making of Spider Princess'.
} 
The story, which illustrates the way in which social pressures force us to conform, adds meaning to the painting but also reverses the readers' expectations of a fairy tale that are set up by the painting's title. In a traditional fairy tale the reader would expect the good, magical princess to be saved by a handsome prince. At the very least, as a fairy tale princess with magical powers, we might expect her to intervene on behalf of her people in the face of a wicked ruler, act as their saviour (symbolised in the painting by the crucifix she holds) and win over her people so that they can live happily ever after. Instead, the Spider Princess tries and fails to reform her people's behaviour by punishing them. As in the case of her use of colour as a semiotic code, Acevedo invites the viewer to draw on their, to some extent preestablished, understandings fairy tales in which magical powers are used to do good work on behalf of the vulnerable, to help them to interpret her work but strikingly overturns convention. Reading the story allegorically and as having a didactic purpose, as fairy stories are intended to be read, the reader-viewer is led to understand, on the one hand that children will become like the people around them and, on the other, that the best way to teach children how to behave is by love and by setting a positive example and not by chastising them. ${ }^{79}$

The story and image may stand alone, but together they significantly enrich one another. However, while the different media enrich one another, they do not 'fit' perfectly together as the painting does not include the Grey Witch. In addition, the story makes no mention of the crucifix which is held aloft by the girl and which is a very prominent element in the painting. The crucifix is usually a symbol of salvation but in the image the forlorn girl does not seem to have been saved and according to the story neither have her people. Looking at the images in the blogpost which inspired 'Spider Princess' we can see that the crucifix takes the place of a balloon in the original image mirroring the way in which the unconscious displaces onto other objects "the "upward drive" of the repressed" ${ }^{80}$ In this case, an element usually associated with happiness, freedom and childhood is substituted for one which stands for authority and an absence of love and salvation. While in some ways the story, the painting and the original images work together to create a 'fuller' story about the Spider Princess and the artistic process, there are also some areas where, just as in

\footnotetext{
${ }^{79}$ On the didactic purpose of early fairy tales Jack Zipes writes: 'Contained in chivalric romances, heroic sagas and epics, chronicles, sermons, poems, lais, and primers during the European Middle Ages, the fairy tale was often a story about miraculous encounters, changes, and initiations illustrating a particular didactic point that the writer wished to express in an entertaining manner'. 'Introduction: Towards a Definition of the Literary Fairy Tale' in The Oxford Companion to Fairy Tales ed. Jack Zipes (Oxford: Oxford University Press, 2015) Online: oxfordreference.com.

${ }^{80}$ Freud, 'Constructions in Analysis', 266.
} 
psychoanalysis, we are reminded that what is recovered is 'full of shifting strata, fragments of living reality, absences more than presences, a mutilated yet still living past involving the elusive presence of the unconscious'. ${ }^{81}$ We are thus reminded of Butler's call for the need to resurrect the skill of reading broken narratives when bearing witness to trauma as well as the fact that these images are open to multiple interpretations and so they reward repeated viewings and sustained engagement. ${ }^{82}$

'Heaven Bound', 'She's Alive' and 'Spider Princess' are examples of the way Acevedo works across different media. The assemblage 'Naughty', on the other hand, showcases her use of intermedia. Like other pieces in the 'Fragmentos' exhibition, 'Naughty' included part of a broken doll. The doll's head, with one eye missing, and the red lips and open mouth again point to sexual abuse. The doll's head was placed on top of a chest of drawers in a way that was reminiscent of a Jack-in-the-box. The drawers of the assemblage were labelled: 'remembered', 'repressed', and, according to the blog, the drawer labelled 'regurgitated' contained the audio recording. ${ }^{, 83}$ Around the missing eye socket were the words 'Tanto le hace el diablo a su hija que le saca un ojo' a saying which criticises parents who spoil their children and which acts as a counterbalance to the message in 'Spider Princess' warning that punishment is not an effective way for improving behaviour. ${ }^{84}$ Around the other eye was the text of a poem. Acevedo has explained that 'Naughty' 'is the manifestation of a poem I originally composed from a collage of Spanish words (some "Mexicanismos"), ${ }^{85}$ The poem was printed in Spanish and English alongside the installation in the gallery, but is also fully integrated into the artwork as the words are written on the dolls head. ${ }^{86}$ As the curator stated in the introductory text to the exhibition: 'In some cases she fills the characters in her work with texts, tattooing them with words, marking them with distress to make it clear that their pasts have been touched and their futures have been truncated'.

The blog notes that there is also an audio recording of the poem built into the assemblage. ${ }^{87}$ In the gallery it was not possible to hear the recording because it was in a glass

\footnotetext{
${ }^{81}$ Kennedy, 'Memory and the Unconscious', 181.

${ }^{82}$ Butler, Undoing Gender, 155.

${ }^{83}$ Pilar Acevedo 'Had I left'.

$84 \mathrm{http}: / /$ cvc.cervantes.es/lengua/refranero/ficha.aspx?Par=59563\&Lng=0

85 Pilar Acevedo, "'Had I left those images hidden in the emotions, I might have been torn to pieces by them." Carl Gustav Jung', http://www.pilaracevedo.com/blog/category/devils\%20dollsbf6c795613 /

http://www.pilaracevedo.com/blog/why-create-art [accessed 8 August 2014].

${ }^{86}$ Pilar Acevedo 'Had I left'.

${ }^{87}$ Pilar Acevedo 'Had I left'.
} 
case and it was difficult to see into the drawers but in the blog Acevedo says: 'I mean for the assemblage to be touched and explored-drawers, which are collages, can be opened. The fact that visitors to the gallery could not interact with Acevedo's intermedia assemblages as she intended or read the story of the 'Spider Princess' points to the challenges faced by multimedia and intermedia artists when showing their work in more 'traditional' gallery settings. Nevertheless, this invitation to touch aims to turn the viewer into an active participant who physically engages with her art as a gateway to other forms of engagement. While access to the artwork is limited for preservation purposes in the gallery setting, the blog enables Acevedo/the viewer to 'complete' the experience as the visitor to the website can hear the poem as well as see some close up images of the artwork, although it is still difficult to see inside the drawers.

In keeping with her interest in psychoanalysis and the effects of trauma on memory, memory in Acevedo's art is represented as fragmented, and consciousness is represented as layered, as illustrated in her use of the drawers in 'Naughty'.

Fig. 5 'Naughty'

On her website she states:

I am especially drawn to childhood memories, which are often illustrated in my work as muddied layers, levels, and fragments. [...] The idea of 'memory as layers' is most evident in my collages, and in my assemblages predominantly through the use of nostalgic objects, drawers, boxes, layers of paper, text, and sound. These pieces are often interactive. The work on canvas and paper illustrates layers through the use of multiple glazes, layering of paper, and the use of several images. ${ }^{88}$

The drawers represent the different layers of the child's consciousness. Together these layers make up her identity, which tries to assert itself in the face of the voice of the abuser who undermines the child by telling her that she is naughty. Whilst parents may tell their children that they are 'naughty' when they misbehave, it is clear from the images in the drawers and the child's incomprehension in the poem that the doll-child is being scolded in this way as a form of abuse and as a means of making her believe that she is responsible for their behaviour and so stop her speaking out. The title of the blog post about the assemblage, 'Had

\footnotetext{
${ }^{88}$ Pilar Acevedo http://www.pilaracevedo.com/.
} 
I left those images hidden in the emotions, I might have been torn to pieces by them' Carl Gustav Jung', reminds us of the importance of helping victims to uncover from their unconscious that which has been repressed so that they can overcome trauma. ${ }^{89}$ The quotation comes from Jung's autobiography Memories, Dreams, Reflections (1962) in a passage in which he describes how he was helped by the discovery that he could manage his emotions by translating them into images. ${ }^{90}$ Acevedo's assemblage puts this technique into practice as the drawers labelled "remembered" and "repressed" contain images that suggest these may help the doll to express her experience of abuse. In the drawer marked 'remembered' it was possible to glimpse a photograph of two dolls in a playground. One is holding a heart-shaped box of chocolates with the words 'Here's my heart' written on the lid. Also in the drawer were two three-dimensional butterflies and a miniature pink doll. These objects and images represent the things that the girl/doll wishes to remember; happy times playing with her best friend and her favourite toy. In the drawer labelled 'repressed' there was a doll's arm, two pieces of what could be flower petals, a drawing of a face with arrows pointing towards it with the words 'I remember'. The following words were pointing at the face: revoltosa, bruja, mentirosa, arrogante, floja. Also in the drawer was a picture of a black heart surrounded by red, orange and yellow so it looked like a sun. These objects and images represent the things that the girl-doll wishes to forget but which remain buried in the bottommost drawer of her mind. They include the hurtful words which have been directed at her and which have hurt her like arrows. The broken arm may represent the memory of an occasion when her own arm was broken as a result of physical abuse or could be a metaphor for the fragmentation of the dolls identity caused by the hurtful words directed at her as in Lacan's conception of the corps morcelé. The latter interpretation would be in keeping with the way in which 'Naughty' highlights the psychological effects of abuse which, the assemblage reminds us, can last far longer than the physical injuries. Nevertheless, overall I think Acevedo tries to place physical and psychological abuse on a par and tries to alert the audience to the need to address all forms of abuse and their impacts

As noted, the drawer marked 'regurgitated' contains the audio of the poem, the text of which is also written onto the side of the doll's face suggesting that the words of the poem are at the forefront of her mind as they play over and over again. According to Freudian psychoanalysis, victims of abuse suffer from a compulsion to relive the trauma. The idea that

\footnotetext{
${ }^{89}$ Pilar Acevedo, 'Had I left'.

${ }^{90}$ Carl Jung, Memories, Dreams, Reflection ed Aniela Jaffé and translated by Richard and Clara Winston (London: Fontana Press, 1995), 201.
} 
the doll-girl is experiencing this kind of traumatic repetition is enforced by the audio version of the poem in which the doll's words are echoed by another haunting voice. The poem describes the thoughts that persist in the doll's injured head as she tries to convince herself that she does not deserve to be abused even if she misbehaves:

¿Y que [sic] de mis berrinches -

y que [sic] de mis verdades?

No es que esté chiflada -

es que soy honesta.'

'And what of my tantrums-

and what of my truths?

I know I'm not wicked -

just honest' ${ }^{91}$

The poem captures both the way in which children treat dolls as if they were human whilst also as objects which can be thrown on the floor. It also reflects the abused child's confusion because the abuser who beats her is also capable of showing affection:

¿Es mi angelito,

o monstro -

son mis santos, o son demonios?

No se [sic], y no me importa.

Is this my guardian angel,

or monster -

are these my saints, or demons?

I don't know and it does not matter. ${ }^{92}$

In a similar vein to 'Heaven Bound', the poem ends with a sense of release, which, in this case, comes through dreams and not through death. The fact that release takes place through dreams reinforces the significance of different layers of consciousness in helping children to process traumatic experiences.

\footnotetext{
91 Pilar Acevedo, 'Had I left'.

92 Pilar Acevedo, 'Had I left'.
} 


\section{Conclusions}

Acevedo's 'Fragmentos' exhibition was a significant breakthrough for the artist. The paintings and assemblages in the exhibition presented a remarkably coherent aesthetic. Form and content were mutually reinforcing and the artwork addressed both the physical and mental effects of child abuse. Of particular interest in the context of contemporary debates about the potential for art to bear witness, was the way Acevedo attempted to bear witness to trauma and engage audiences without resorting to shock tactics, and without turning trauma into a spectacle that might feed our fascination with seeing pain. Her work confirms Hallas and Guerin's assertions that the capacity for bearing witness to trauma is not limited to documentary or even realist images, nor to first-hand witnesses. Indeed, Acevedo's practice presents bearing witness as an on-going process, which she hopes will be taken up by the viewers of her work, rather than a one-off event. Acevedo's work is also of interest as a case study within the context of trauma and memory studies because it moves away from the traditional focus on large-scale traumatic historical events, which have marked the public imaginary, such as the holocaust or 9/11. Moreover, it shows a way of moving beyond privileging individual accounts by placing them in the context of similar experiences without completely erasing the individual narratives recognised on her blog.

Drawing on comments made by Kristeva about the use of signifiers for promoting understanding and observations by Kilby about the use of 'testimonial images' in constituting active viewers, we have examined Acevedo's use of uncanny and fragmented dolls and other signifiers to promote the kind of identification with the other that lies at the heart of bearing witness. Departing from the traditions of abject art, Acevedo replaced actual bodies and body parts with fragmented dolls, which stand in for the victims of child abuse. Her art, therefore, did not cause the beholder to faint or avert their gaze but, to borrow Kristeva's words, to 'understand, react, or accept'. 93 If a sense of fascination is maintained, it lies in the enticement to the beholder to seek to decode the images, in order better to understand what $\mathrm{s} / \mathrm{h}$ is seeing. Acevedo's practices of using 'testimonial' images, colour as a semiotic code, signifiers including dolls, fairy tales, iconic images such as red stilettos as well as multimedia signifiers such as the music in 'She's Alive' therefore form the basis of an important strategy for engaging viewers without risking alienating them or engaging their voyeuristic gaze.

\footnotetext{
${ }^{93}$ Kristeva, Powers, 4 and 3.
} 
These techniques point to new, potentially more effective, ways in which art can deal with the challenge of representing and bearing witness to trauma whilst still leaving space for aesthetic appreciation of the work.

Eschewing realistic images of abuse, the dolls in Acevedo's work bring child abuse into 'iconic presence', raising public awareness and making it clear that turning a blind eye is unacceptable. Each broken doll is an exhortation to enter a different level of meaning and a prompt for identifying with, and bearing witness to, the experiences and trauma of another. The use of dolls means that the difficult subject of child abuse is addressed in such a way that the viewer is not placed in the position of voyeur and is not confronted with graphic images of abuse from which they might recoil and disengage, or engage with abusively. In this respect, Acevedo's art addresses Lusty's criticisms of surrealist art and picks up on the legacy of Cindy Sherman, drawing on the overlapping traditions of surrealism, abject art and psychoanalysis, but going one step further by not relying on shock tactics, erasing the child's experience, nor objectifying the female child.

Finally, Acevedo's use of 'open' images and her multimedia and intermedia approach represent another important strategy for engaging the viewer, making him/her an active participant in the production of meanings and someone who occupies a role similar to that of the psychoanalyst who reads the broken narratives as a means to heal and bear witness to trauma. Her work is an example of the growing significance and potential of multimedia approaches which enable artists like Acevedo to supplement (or even replace) the gallery experience. As this analysis of her multimedia 'Fragmentos' exhibition has shown, Acevedo's work opens up new ways of seeing and experiencing art but also new ways of bearing witness. 